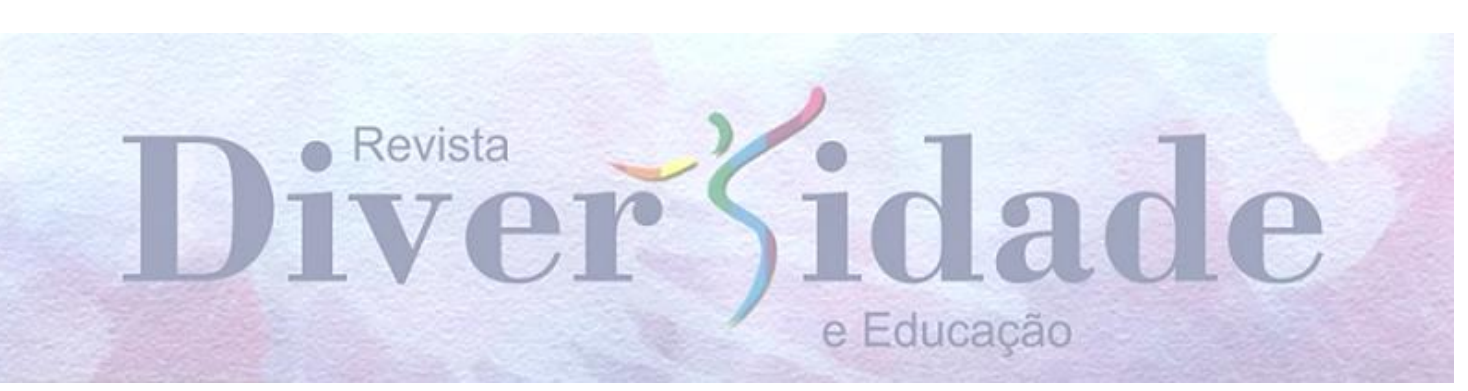

\title{
EDUCANDO ENTIDADES: \\ TERREIROS DE QUIMBANDA COMO ESPAÇOS EDUCATIVOS
}

\author{
EDUCACIÓN DE LAS ENTIDADES: \\ LAS TERRAZAS DE QUIMBANDA COMO ESPACIOS EDUCATIVOS
}

EDUCATING ENTITIES:

THE TERRACES OF QUIMBANDA AS EDUCATIONAL SPACES

\author{
Rodrigo Lemos Soares ${ }^{1}$ \\ Ariana Souza Cavalheiro ${ }^{2}$ \\ Denise Marcos Bussoletti ${ }^{3}$
}

\section{RESUMO}

Entendendo que os Terreiros de Quimbanda como espaços educativos, esta pesquisa aponta resultados de análises de seis visitas a dois Centros Espíritas de Quimbanda do município do Rio Grande, Rio Grande do Sul. O objetivo geral é discutir os modos como são passados ensinamentos sobre as mitologias e movimentos de exus e pombagiras nos terreiros visitados. Os dados foram registrados em diários de campo, escritos ao longo de três visitas em cada local durante o ano de 2017. Referente às análises, os ensinamentos são passados pela oralidade, além disso, é possível dizer que as pessoas esperam por comportamentos específicos dos(as) médiuns, por possuírem algum conhecimento sobre as entidades e isso reflete nos fazeres, na execução dos gestos e das danças de chegada, tanto de exus, quanto de pombagiras. Por fim, em relação aos ensinamentos os pais ou mães de santo recorrem às mitologias que envolvem os exus e pombagiras.

PALAVRAS-CHAVE: Educação. Pedagogias culturais. Quimbanda. Danças.

\section{RESUMEN}

Entender que el cementado Quimbanda como espacios educativos, esta investigación apunta análisis resultados de seis visitas a dos centros espiritistas de Quimbanda ciudad de Rio Grande, Rio Grande do Sul. El objetivo general es analizar las formas en que se pasan las enseñanzas en las mitologías y los movimientos de exus y pombagiras en las terrazas. Los datos fueron registrados en diarios de campo escrito en el transcurso de tres visitas en cada localización durante el año de 2017. Para el análisis, las enseñanzas se pasan por la oralidad, además, es posible decir lo que gente espera comportamientos específicos de los medios, por tener alguno conocimiento de las entidades y esto se refleja en la realización, en la ejecución de los gestos y los bailes de su llegada, ambos

\footnotetext{
${ }^{1}$ Mestre em História e Educação em Ciências. Universidade Federal de Pelotas, Pelotas, Rio Grande do Sul, Brasil.

${ }^{2}$ Mestre em Educação. Universidade Federal do Rio Grande, Rio Grande, Rio Grande do Sul, Brasil.

${ }^{3}$ Doutora em Psicologia.Universidade Federal de Pelotas, Pelotas, Rio Grande do Sul, Brasil.
} 
de exus, a partir de pombagiras. Finalmente, en relación con las enseñanzas los padres o madres de Santo recurren a la mitología que los exus y pombagiras.

PALABRAS-CLAVE: Educación. Pedagogías culturales. Quimbanda. Bailes.

\section{ABSTRACT}

Understanding that the cemented Quimbanda as educational spaces, this research points analysis results of six visits to two centers Spiritualists of Quimbanda city of Rio Grande, Rio Grande do Sul. The general objective is to discuss the ways in which are passed teachings on the mythologies and movements of exus and pombagiras on the terraces. The data were recorded in field journals written over the course of three visits in each location during the year of 2017. For the analyses, the teachings are passed by orality, moreover, it is possible to say what people expect for specific behaviors of the mediums, by having some knowledge of the entities and this reflects in the making, in the execution of the gestures and the dances of arrival, both of exus, as of pombagiras. Finally, in relation to the teachings or Holy mothers parents resort to mythology involving the exus and pombagiras.

KEYWORDS: Education. Cultural pedagogies. Quimbanda. Dances.

$$
* * *
$$

\section{Abrindo os trabalhos...}

"Deu meia-noite a lua se escondeu lá na encruzilhada dando a sua gargalhada pomba-gira apareceu [...] "Lá na encruza existe um homem valente com sua capa e cartola e seu punhal entre os dentes[...]"'4 (Autor(a) desconhecido(a))

Ao abrir os trabalhos com esses pontos $\operatorname{cantados}^{5}$, demarco ${ }^{6}$ que esta pesquisa parte da percepção de que nos Terreiros de Quimbanda ocorrem determinadas formas de educação não escolarizada ${ }^{7}$. O estudo, por ora apresentado, é resultado de análises de seis visitas a dois Centros Espíritas de Quimbanda do município do Rio Grande, Rio Grande do Sul. Na base da pesquisa estão questionamentos sobre quais os possíveis modos de educação, presentes nestes locais e, de como os saberes são traduzidos pelos(as) filhos(as) de santo das casas de religião ao exibirem simbolicamente a aprendizagem através de comportamentos e danças das entidades incorporadas durante os ritos. Aponto estes questionamentos, a partir do campo teórico dos Estudos

${ }^{4}$ Este ponto foi entoado durante às visitas. Ponto de Exú Tranca Rua - Lá na encruza existe um homem valente. Disponível em: < https://www.youtube.com/watch?v=Hpw_5E4lwJM> Acesso em: 18/09/2018.

${ }^{5}$ Pontos cantados são orações ritmadas que servem, dentre outras funções, para chamarem as entidades dos terreiros, bem como, são artefatos que por meio de suas letras, ensinam modos de agir e compreender às dinâmicas dos terreiros.

${ }^{6} \mathrm{~A}$ escrita do texto se dará em primeira pessoa, tendo em vista, que somente o primeiro autor foi a campo. ${ }^{7}$ As discussões referentes aos conceitos de Educação Formal; Educação não formal; Educação informal não serão desenvolvidas neste texto. Contudo, o termo por nós utilizado refere-se a questão de que os terreiros são espaços legalizados, porém não escolarizados. Dito isso, a educação não escolarizada, existente nos terreiros, dialoga com as proposições de Gohn (2005), Garcia (2005) e Libâneo (1998). 
Culturais $^{8}$ nas suas vertentes pós-estruturalistas ${ }^{9}$, assumindo as pedagogias enquanto processos sociais que ensinam, que estão implicadas na produção e interlocução de sentidos atribuídos a estes espaços.

O objetivo geral é discutir os modos como são passados ensinamentos sobre as mitologias e movimentos de exus e pombagiras ${ }^{10}$ nos terreiros visitados. Outro rastro de intenção da pesquisa está em ver os corpos como “[...] memória mutante das leis e dos códigos de cada cultura, registro das soluções e dos limites científicos e tecnológicos de cada época, o corpo não cessa de ser fabricado ao longo do tempo" (SANT'ANNA, 1995, p. 12). Percebo então que não há mais lugar para pensarmos as religiões de matriz afro, sem inter-relações. É através dessas inter-relações que se torna possível pensar nessa vertente religiosa como um saber sujeitado, que desloca certezas e produz outras verdades no pensar questões educativas na contemporaneidade, destacando facetas que ainda insistem em ser silenciadas, não entrando na ordem discursiva do que se entende por verdadeiro neste tempo. Nesse sentido destaco que "[...] o que importa é entendermos como chegamos a ser o que somos e, a partir daí, contestarmos aquilo que somos" (HENNING; HENNING, 2012) através das culturas que nos afetam.

Os espaços das religiosidades afro são uma possibilidade de investigação que permitem encontrar elementos acerca das relações de poder, resistência e de verdade na educação retomando Foucault (1997, p. 91) ao escrever que “[...] lá onde há poder há resistência [...]". Compreendo que os estudos foucaultianos permitem não reproduzir e naturalizar os fatos históricos referentes às religiões afro, mas evidenciar as articulações e os jogos de poder para chegarmos a sermos aquilo que somos, como Foucault (1979) me ajuda a pensar. Os significados que temos de nós mesmos, enquanto religiosos ou mesmo enquanto sujeitos, estão afetados pelos signos que foram forjados no campo sociocultural. É no palco, no jogo, no reconhecimento ou na ausência deste, que constituímos nossas posições de sujeito e identidades.

\footnotetext{
${ }^{8}$ Os Estudos Culturais podem ser entendidos como um campo de teorização e investigação que se utiliza de diversas disciplinas para estudar os processos de produção cultural da sociedade situando-se nas conexões entre cultura, significação, identidade e poder (SILVA, 2005).

${ }^{9}$ Para Silva (2005) o pós-estruturalismo pode ser entendido como "[...] uma continuidade e, ao mesmo tempo, como uma transformação relativamente ao estruturalismo" (p.118). Concebendo a linguagem como "sistema de significação", não neutro, que diz respeito à mudança de uma noção de fixidez da significação para uma na qual a linguagem é fluida, contingente e instável. O sujeito visto como resultado de um processo de produção cultural e social.

${ }^{10}$ Segundo o sincretismo religioso os Exus são espíritos que já encarnaram na terra. Na sua maioria, viveram de modo a prejudicar seriamente sua evolução espiritual, sendo assim estes espíritos optaram por prosseguir sua evolução espiritual através da prática da caridade. Já, as Pombo-Giras é corruptela do termo "Bombogira" que significa em Nagô, Exu. Dizem que Pomba-Gira é uma mulher da rua, uma prostituta. Pombo-Gira é um Exu Feminino ou Exu mulher.
} 


\section{Dançando conforme os pontos...}

Para construção de mais esta pedagogia cultural recorri aos saberes que me trouxeram até aqui, ou seja, minhas memórias, experiências e olhares à Quimbanda como momentos em que apreendi e aprendi pelos encontros, vivências, nos quais se valorizam as trocas e interlocuções. Dialogo com Portelli (2010), ao expor que a construção de redes de memórias que pressupõe sujeitos que lembram e indicam outros(as) formando nosso corpus de análise implica em um cuidado para com a singularidade das memórias dos(as) depoentes, de suas histórias.

Para produção dos dados utilizei-me, basicamente, mas não exclusivamente dos diários de campo. Essa escolha deve-se ao fato de que as observações auxiliaram-me a formular situações "problemas", que pudessem conduzir meus olhares àqueles ambientes com outras visões de mundo, ou que ao menos, escapassem das verdades que já havia formulado ao longo da minha vida religiosa. Coloco-me na retaguarda dessa produção para possibilitar destacar e questionar verdades outras que são construídas pela Quimbanda e os(as) sujeitos(as) produzidos(as) com e a partir de experiências ritualísticas, entendendo que não são saberes "naturais", "desde sempre aí" (VEIGANETO, 2011), mas sim, percebendo-os como construções de uma época. E são essas construções que me propus a enfrentar através dessa pesquisa, ou como diria Foucault (2005), me dispus às "asperezas", compreendendo as condições de possibilidade que ensejam a sua entrada na ordem do dizível.

Destaco que os terreiros não foram aleatoriamente escolhidos. Busquei na liga de terreiros aqueles que trabalham com Quimbanda. Cheguei ao número de 14 e destes, dois dispuseram-se para que começassem às visitações. Registro, no entanto, que todos trabalham com Umbanda também. Os dados foram registrados em diários de campo, escritos ao longo das visitas aos Terreiros de Quimbanda (três em cada local) durante o primeiro semestre de 2017, salientando que os relatos foram escritos a partir de observações em dias de trabalhos fechados ${ }^{11}$ ao público, uma vez que, nestes momentos

${ }^{11}$ A indicação de observar os dias fechados me foi dada pelas duas mães de santo, sob a justificativa de que nestes dias elas teriam tempo para ajudar-me, caso fosse necessário, bem como, são nestes momentos em que ocorrem estudos sobre religiosidades e espiritualidades, segundo elas. São nos cultos fechados também, que são marcados momentos para que se façam trabalhos (feitiços) para aqueles(as) consulentes 
ocorrem os estudos sobre a feitura das entidades. Nos dois centros as mulheres (pombagiras) foram chamadas primeiro. Demarco, também, que a frente de um dos centros é compartilhada entre o exú Tranca Ruas das Almas e pela Maria Padilha das Almas, enquanto, que o outro é comandado pela pombagira Maria Molambo. A seguir apresento um quadro de sistematização das visitas:

\begin{tabular}{|c|c|c|}
\hline Visita: & $\begin{array}{c}\text { Reino de Bará e Oyá } \\
\text { (Tranca Ruas das Almas e Maria Padilha das Almas) }\end{array}$ & $\begin{array}{c}\text { Reino de Obá } \\
\text { (Maria Molambo) }\end{array}$ \\
\hline 1 & $25 / 04 / 2017$ & $04 / 05 / 2017$ \\
\hline 2 & $16 / 05 / 2017$ & $08 / 06 / 2017$ \\
\hline 3 & $13 / 06 / 2017$ & $06 / 07 / 2017$ \\
\hline
\end{tabular}

Fonte: arquivo pessoal dos(as) pesquisadores.

Entre as possibilidades de escolhas, por se tratar de uma investigação de culturas cotidianas específicas e, nesse momento, experimental de grupos religiosos e suas relações de ensino escolhi o diário de campo como uma ferramenta de registros e interlocuções para/da/na pesquisa. A construção dos diários de campo implicou na produção de documentos onde registrei os movimentos, as leituras, os tempos, espaços e das observações, enfim, dos olhares possíveis, aqueles momentos em que muitas coisas estavam latentes em escapar, devido a multiplicidade de acontecimentos. Nos diários contemplei a "[...] descrição das pessoas, objetos, lugares, atividades, acontecimentos e conversas" (BOGDAN; BIKLEN, 1994), fomentando os registros dos saberes e fazeres, dos contextos que ocorreram ao longo das visitas, apontando cenas dos momentos e das narrativas capturadas dos(as) praticantes (CERTEAU, 2012).

\section{Sobre a Quimbanda...}

A Quimbanda tem sido tratada como espaço do mal - "à esquerda” (BARROS, 2007) por ser vinculada a magia negra e assim, oposta a Umbanda (que estaria à direita), porém alguns estudos, como o de Prandi (1996) caracterizam estas duas vertentes como complementares. Ademais, é estudada com relações ao africanismo religioso, como mais uma ramificação das disseminações religiosas brasileiras (BARROS, 2007), sendo igualmente denominada de Macumba, ou linha cruzada pelos desdobramentos e fusões com a Umbanda (CANCLINI, 2006). Dentre as características atribuídas a ela estão: a evidenciação aos Exus e Pombagiras, os tratos com emolação de animais (SCHIAVO, 2007), fatores que a colocam em alguns estudos, como espaço do

que no dia de trabalhos abertos foram buscar ajuda por parte do centro, através das entidades que lá chegam. 
profano (SANTOS, 2015) e do infame (FOUCAULT, 2006), chegando a ser postulada em um terceiro subplano, em uma pretensa hierarquia religiosa. Somado a isso, o pleiteamento de extinção da mesma, em prol de um ideal de moralidade religioso (ORTIZ, 1999).

Enfatizo aqui o papel dessa vertente religiosa como veiculadora de pedagogias culturais, a partir do momento que ensinam sobre comportamentos, produzindo, assim, subjetividades, identidades e saberes. A afirmativa deve-se pelo diálogo com Steinberg e Kincheloe (2001) ao indicarem que pedagogia cultural supõe que a educação ocorra “[...] numa variedade de áreas sociais, incluindo, mas não se limitando à escolar. Áreas pedagógicas são aqueles lugares onde o poder é organizado e difundido" (STEINBERG; KINCHELOE, 2001, p.14). Envolver a Quimbanda como um potente artefato pedagógico dá-se por perceber que as trajetórias destes grupos religiosos na cidade de Rio Grande, articulados com suas experiências de pertencimento e produção de sujeitos nestes espaços educativos não escolares, é território ainda pouco explorado ou silenciado. Nessa perspectiva, é possível lançar mão daquilo que Foucault (2005, p. 11) pontua como "[...] saberes sujeitados", isto é, que estão a nossa volta, que foram construídos há longa data, mas que são ocultados, desqualificados, por vezes, não entram na ordem do dizível, mas que podem apresentar-se como uma potente ferramenta para/de discussão. Como se tal dispersão não bastasse, observam-se também diferentes focos de interesse: questões de raça e etnia, de gênero, etc.

\section{Saberes e fazeres: ensinamentos e as danças das entidades}

Recorro a Geertz (2008), ao afirmar que as descrições devem ser detalhadas, no intuito de diferenciarmos as narrativas, símbolos, expressões, ambientes, as cronologias, as culturas e as condutas do grupo social pesquisado é preciso esmiuçar os significados culturais. O Reino de Bará e Oyá possui muitos enfeites nas paredes, imagens de santos(as) católicos(as) e orixás, documentos (como o alvará de liberação para realização dos trabalhos), fotos de pessoas, que inclusive, não estão mais lá (alguns/mas estão mortos - segundo a mãe de santo). No Reino de Oyá a presença de imagens dessa orixá, o quarto de santo e a tronqueira ficam fechados o tempo todo. Segundo Bosi (2008) estes apontamentos demarcam “[...] aquilo que é essência da cultura, o poder de tornar presentes os seres que se ausentaram do nosso cotidiano" (BOSI, 2008, p. 25). Questões que um gravador não captaria, alguns sentidos e significados, estão descritos nos diários. Sobre os saberes e fazeres dos ritos e danças, vejamos abaixo: 
[...] A sacerdotisa da casa, após ensinar sobre os significados dos movimentos vai narrando as mitologias das entidades dos filhos mais velhos da casa (nesse sentido, o mais velho não é em idade, mas sim em tempo de casa, de desenvolvido). Ao longo das batidas do tamboreiro ela vai induzindo sensações. Segundo ela "os cavalos devem dançar conforme a vida da sua entidade, sua feitura e desenvolvimento no corpo daquele sujeito (Diário de campo REINO DE OBÁ - 04/05/2017).

Partindo desse excerto, os terreiros são entendidos, nesta pesquisa, como instituições culturais. Neles ocorrem inúmeras práticas ritualísticas que influenciam nos modos como os sujeitos se colocam no mundo (CAPUTO, 2012). A educação nestes espaços está assentada em uma premissa de que: “[...] as cosmologias das religiões de matriz africana são concebidas num princípio tridimensional simbiótico entre homemnatureza-fé" (SANTOS; GONÇALVES, 2011, p. 14). Nesse sentido, os saberes que são repassados nestes locais perpassam essa trilogia, uma vez que é ela que orienta os caminhos a serem seguidos nos terreiros.

$\mathrm{O}$ fato de compreendê-los, enquanto instituições culturais decorre dos entendimentos que eles preconizam mediações entre culturas e conhecimentos e, assim, possibilitam a pedagogização dos sujeitos, a partir de diferentes contextos que nos educam, especificamente, neste caso, ambientes não formais de educação ou não escolarizados. Assim, os terreiros, estão sendo entendidos como espaços profícuos às investigações sobre o ensino, sem com isso pensar que eles substituem as escolas, porém estão alocados de modo paralelo a estas. Trato-os, então, como campos possíveis para atuação de educadores(as), em diálogo com os saberes destes locais, por compreender que os espaços não escolarizados possuem planejamentos, conduzidos por intencionalidades não necessariamente formalizadas (LIBÂNEO, 1998). Além disso, estes locais possuem suas lógicas acerca do que e como ensinar, vejamos:

[...] Primeiramente vocês precisam pegar o ritmo nas mãos, para emanar energia durante as palmas, nos pontos. Precisam cantar os pontos para que a energia flua na corrente e que isso chegue à assistência. Precisam deixar os compassos movimentarem seus corpos - assim óh - para um lado e para o outro, pois isso é uma festa para as entidades, eles estão chegando na terra e assim como todos nós quando chegamos em algum lugar querem ser bem recebidos (Diário de campo REINO DE BARÁ E OYÁ - 16/05/2017).

Conforme descrito na nota de diário, ocorre uma sequencialidade dos modos e comportamentos. Cada saber é intencional. Na educação não formal existe a intencionalidade de educar, a partir de planejamentos que seguem conteúdos específicos que buscam cumprir com alguma organização, respondendo a alguma lógica de ensinamento, fator que implica em reconhecer objetivos diferentes para cada conteúdo (LIBÂNEO, 1998). No entanto, mantem a característica de flexibilidade tanto de 
espaços, quanto de tempo. Nela, o processo de ensinar é múltiplo, não tendo como característica a adoção de uma sequência, tampouco está preocupada em seguir um sistema com referências generalistas (LIBÂNEO, 1998). Seus conteúdos são abordados de acordo com as necessidades e desenvolvimento dos sujeitos partícipes dos processos educativos. Porém, destaco, que alguns modelos de educação não formal, podem se assemelhar a formalidade da escola, contudo, ocorrendo em ambientes que não sejam os escolares.

[...] aqui não é um colégio, mas tudo tem sua hora e momento. Tu nunca pula um fundamento, cada aprendizagem tem sua fase e momento de ritual para acontecer, estar pronto implica em ter aprendido sobre as histórias da religião, das coisas que fazemos. Nada é de qualquer jeito, um aprendizado puxa e depende de outro (Diário de campo REINO DE BARÁ E OYÁ - 25/ 04/ 2017).

Segundo a participante, o terreiro não é um colégio, porém possui organização espaço-temporal, tal qual as instituições escolares. Os sabres são repassados de forma processual. Além disso, que o conhecimentos estão interligados, não podendo pular etapas. Dito isso, compreendo que tal narrativa dialoga com a noção de educação não formal pelo fato de que ela compreende dentro de suas características uma noção de educação global, que inclua todas as possibilidades de experiência dos sujeitos, reconhecendo que "[...] tais elementos impregnam a própria natureza dos conteúdos e métodos de ensino" (LIBÂNEO, 1998, p. 85).

Ao considerar essa afirmação mais as experiências dos sujeitos é que se torna possível pensar nos terreiros enquanto espaços educacionais, compreendendo neles, oportunidades de articulação de saberes, sem sobreposição de um, em relação ao outro. Os terreiros então assumem a função de educar, a partir de saberes que orientam não só práticas religiosas, mas modos de ser e estar no mundo e que são marcados por referências a variadas temporalidades, que são produzidas, a partir de referências ao passado, ao histórico, ao mitológico. Os saberes difundem-se com o local, as culturas daqueles(as) que participam dos momentos ditos religiosos, conforme leitura do excerto abaixo.

[...] com o tempo, o povo da assistência já sabe se vocês estão prestes a incorporar, se as entidades de vocês estão bem ou viradas. Os movimentos de vocês falarão tudo isso e deixarão vocês expostos. [...] vai aparecer nos movimentos de vocês. É a mesma coisa quando vocês chegam aqui em casa, eu percebo aqueles que querem ficar quietos, os que querem fazer alguma brincadeira, aqueles que só no abraço dizem tudo (todos riram). Viram, isso é muito importante (Diário de campo REINO DE BARÁ E OYÁ 13/06/2017). 
$\mathrm{Na}$ esteira do que foi dito pela mãe de santo, é possível compreender que as lógicas de ensino apresentam uma sequência lógica a ponto de serem (pre)visíveis alguns acontecimentos. Para além disso, ela afirma perceber os sentimentos dos(as) participantes reiterando a ideia de que os terreiros, instituições culturais, são conduzidos por pessoas denominadas de mediadores(as) culturais (CAPUTO, 2012). O que não implica dizer que os(as) dirigentes dos mesmos não possuam formação acadêmica, mas em grifar que não são chamados(as) de professores(as). Enquanto ambientes educativos são entendidos como locais para experimentação cultural, por um viés de educação não formal, destinados a ensinar o que muitas vezes não se passa nas escolas (LIBÂNEO, 1998).

[...] no terreiro tu aprende muita coisa é uma extensão da tua casa e, tens que saber conviver com o que todos sabem, todo mundo aqui aprende e ensina. Aqui, começa pela cozinha, tu precisa saber servir as entidades, depois tem os pontos, as rezas, as dinâmicas da casa, além dos rituais de chegada e saída, as danças, as vidas das entidades, isso fala muito da casa é básico (Diário de campo REINO DE OBÁ - 08/ 06/2017).

Além disso, os terreiros são espaços que podem ser compreendidos como patrimônios ${ }^{12}$ culturais que possuem, dentre seus propósitos, manter memórias, sinalizar a existência de culturas específicas, acolhendo todos(as) aqueles(as) que deles queiram fazer parte ou por eles aprender. Dialogo com Gohn (2005), ao expor que a educação não-formal preconiza processos em três extensões, primeiro porque envolve uma aprendizagem de cunho político dos sujeitos visando a uma educação para cidadania; segundo porque, auxilia na formação para organização em comunidade, uma vez que a aprendizagem parte das práticas de um coletivo específico; terceiro por não desprezar os conteúdos da educação formal, porém, opera com eles em diálogo, a partir de espaços e tempos que compreendam as necessidades dos sujeitos.

[...] Não preparo vocês para serem bailarinas, mas sim para saberem receber suas entidades. Vai de passo em passo, primeiro estuda a História da religião, quando souberes das tuas entidades, quem são elas, estuda algo sobre elas e isso tudo só tem a te ajudar, porque elas perceberão que tu estás pronta para recebê-las. Daí os movimentos vão acontecendo e saindo conforme elas vão te doutrinando e dominando teu corpo. É por isso, que com o tempo alguns de vocês mudam o jeito de chegada dos seus exus e pombagiras (Diário de campo REINO DE OBÁ - 06/07/2017).

Gohn (2005) separa a educação não formal em dois grupos, o primeiro é o da “educação popular", com destaque para educação de jovens e adultos, aquela ocorrida

${ }^{12}$ Saliento que não me detive às discussões relacionadas a temática, tampouco busquei aprofunda-la na conceituação acerca de patrimônios e processos de patrimonialização, apenas sinalizo que estes debates já exisem. 
fora do contexto escolar. O segundo grupo é o educação propiciada pela "participação social", baseado na coletividade, em prol da aprendizagem de conteúdos de uma cultura específica, como é o caso dos terreiros, embora não despreze os saberes ensinados nas escolas. Estes grupos demarcam que a educação não formal, não é algo do nosso tempo, ela possui discursos pedagógicos que contemplam desde as culturas iniciais, até as produzidas atualmente, sem que uma anule a outra. Para Garcia (2005) a educação não formal “[...] pode ser a busca de uma outra dimensão educacional, que se diferencia sem a preocupação de negar a educação formal [...] busca considerar contribuições vindas de experiências que não são priorizadas na educação formal" (GARCIA, 2005, p. 27) pode ser pensada por uma característica, a não ser tão verticalidade. Isso porque, ela preconiza interações de diferentes ordens, nas quais os ensinamentos ocorrem em múltiplos vetores e, mais que isso, em um sistema onde todos(as) ensinam todos(as). Nesse caso, existe outro motivo para alocar os terreiros tanto como espaços educativos, quanto como instituições culturais que pedagogizam sujeitos.

\section{O dançado e o apreendido: os ensinamentos por entre as saias e capas...}

Expostas estas considerações, afirmamos que nos terreiros, os ensinos, as pedagogias e metodologias, são da ordem da não formalidade, ou como exposto pelos(as) dirigentes dos mesmos, da não escolaridade. A educação não formal está para os terreiros, como os ensinos de danças está para produção dos corpos, com pedagogias que partem de conhecimentos específicos destes locais. No entanto, de qualquer modo, a educação ocorre diretamente nos corpos, sobre eles preconizando certa docilidade (FOUCAULT, 2000). A educação não formal interage com a produção de memórias, advindas das regras que orientam culturas e, assim, os corpos não param de ser produzidos, a partir de influências específicas de cada tempo (SANT`ANNA, 1995). Eles - os corpos são, por assim dizer, pedagogizados o tempo todo, por via da oralidade. Por fim, em relação aos ensinamentos foi possível perceber que os pais ou mães de santo recorrem às mitologias que envolvem os exus e pombagiras desenvolvidos nos Terreiros estudados, nos quais todos(as) ensinam, nestes espaços educativos.

\section{Guias teóricos(as)...}


BOGDAN, Robert; BIKLEN, Sari Knopp. Investigação qualitativa em educação. [Trad.] ALVARES, M. J.; SANTOS, S. B.; BAPTISTA, T. M. Porto, Portugal: Porto Editora, LDA, 1994.

BOSI, Ecléa. Cultura de massa e cultura popular: leituras de operárias. 12. ed. Petrópolis, RJ: Vozes, 2008.

CANCLINI, Néstor Garcia. Culturas híbridas. São Paulo: Edusp, 2006.

CAPUTO, Stela Guedes. Educação nos terreiros: e como a escola se relaciona com crianças de candomblé/ Stela Guedes Caputo. - 1. Ed. - Rio de Janeiro: Pallas, 2012.

CERTEAU, Michel. de. A invenção do cotidiano: 1. Arte de fazer. 18 ed. [Trad.] ALVES, E. F. Petrópolis, RJ: Vozes, 2012.

FOUCAULT, Michel. A vida dos homens infames. In: Ditos e Escritos IV: Estratégia poder-saber. [Trad.] RIBEIRO, V. L. A. R. 2 ed. Rio de Janeiro: Forense Universitária, 2006. pp. 203-222.

FOUCAULT, Michel. Em defesa da Sociedade: curso no Collége de France. [Trad.] GALVÃO, M. E. A. P. São Paulo: WMF Martins Fontes, 2005.

FOUCAULT, Michel. A arqueologia do saber. Rio de Janeiro: Forense-Universitária. $2^{\mathrm{a}}$ e $6^{\mathrm{a}}$ ed. [Trad.] NEVES, L. F. B. 2000.

FOUCAULT, Michel. História da Sexualidade I: a vontade de saber. [Trad.] ALBUQUERQUE, M. T. C.; ALBUQUERQUE, J. A. G. Rio de Janeiro: Graal: 1997. FOUCAULT, Michel. A ordem do discurso. [Trad.] SAMPAIO, L. F. A. São Paulo: Loyola, 1996.

FOUCAULT, Michel. Microfísica do Poder. [Trad.] MACHADO, R. Rio de Janeiro: Graal, 1979.

GARCIA, Valéria Aroeira. Um sobrevôo: o conceito de educação não formal. In: PARK, M. B.; FERNANDES, R. S. [Orgs.]. Educação Não-Formal: Contextos, Percursos e Sujeitos. Campinas, SP: Unicamp - Editora Setembro, 2005.

GEERTZ, Clifford. A interpretação das culturas. Rio de Janeiro: LTC, 2008.

GOHN, Maria da Glória. Educação Não-Formal e Cultura Política. 3 ed. São Paulo: Cortez, 2005 (Coleção questões da Nossa época; v. 71).

HENNING, Paula Corrêa; CHASSOT, Ático Inácio. Por uma ciência do riso e da sabedoria. Espaço Acadêmico - No 109 - jun. 2010. Maringá: UEM. pp. 44 - 50.

HENNING, Clarissa Corrêa; HENNING, Paula Corrêa. Sobre verdades inventadas e mentiras potentes: práticas de si como espaço de resistência. In.: HENNING, P. [Org.]. Cultura, ambiente e sociedade. Rio Grande: Universidade Federal de Rio Grande, 2012. pp. 9-32.

LARROSA, Jorge Bondía. Notas sobre a experiência e o saber de experiência. Revista Brasileira de Educação. Jan-Fev-Mar-Abr. n 19.2002. pp. 20 - 28.

LIBÂNEO, José Carlos. Pedagogia e pedagogos para quê? São Paulo: Cortez, 1998. 
ORTIZ, Renato. A morte branca do feiticeiro negro: Umbanda e sociedade brasileira. São Paulo: Brasiliense. 1999.

PORTELLI, Alessandro. Ensaios de História Oral [seleção de textos] Alessandro Portelli e Ricardo Santhiago; [Trad.] CÁSSIO, F. L. e SANTHIAGO R. S. São Paulo: Letra e Voz, 2010.

PRANDI, Reginaldo. Pombagira e as faces inconfessas do Brasil. In.: Herdeiras do Axé: sociologia das religiões afro-brasileiras. São Paulo, Hucitec, 1996, Capítulo IV, pp. 139-164.

SANT`ANNA, Denise Bernuzzi. Políticas do corpo. São Paulo: Estação Liberdade, 1995.

SANTOS, Josiclei Souza. O sagrado e a diferença negra em oração da cabra preta, de Bruno de Menezes. Revista Ecos, vol.18, Ano XII, n 01. 2015. pp. 146 - 165.

SANTOS, Rosalira Oliveira dos; GONÇALVES, Antonio Giovanni Boaes. A natureza e seus significados entre adeptos das religiões afro-brasileiras. Anais do III Encontro Nacional do GT História das Religiões e das Religiosidades - ANPUH. In.: Revista Brasileira de História das Religiões. Maringá (PR) vol. III, nº. 9, jan/2011.

SCHIAVO, Luigi. Religião e diversidade sociocultural. Caminhos, Goiânia, v. 5, n. 1, pp. 7-12, jan./jun. 2007.

SILVA, Tomáz Tadeu da. Documentos de identidade: uma introdução às teorias do currículo. 2.ed. Belo Horizonte: Autêntica, 2005, pp. 111-124.

STEINBERG, Susan; KINCHELOE, Joe. [Orgs.] Cultura infantil: a construção corporativa da infância. Rio de Janeiro: Ed. Civilização Brasileira, 2001.

VEIGA - NETO, Alfredo. Foucault \& a Educação. Belo Horizonte: Autentica, 2011. 